\title{
EGFR isoforms and gene regulation in human endometrial cancer cells
}

\author{
Lina Albitar1,5, Gavin Pickett2, Marilee Morgan2,6, Jason A Wilken³, Nita J Maihle ${ }^{3,4}$ and Kimberly K Leslie*1,7
}

\begin{abstract}
Background: Epidermal growth factor (EGF) and its receptor (EGFR) constitute a principal growth-promoting pathway in endometrial cancer cells. Pre-clinical studies were undertaken to compare the expression of EGFR isoforms and the downstream effects of activating or blocking EGFR function in Ishikawa $\mathrm{H}$ cells, derived from a moderately differentiated type I endometrioid adenocarcinoma, or in Hec50co cells, derived from a poorly differentiated type II adenocarcinoma with papillary serous sub-differentiation.

Results: We investigated whether EGFR mutations are present in the tyrosine kinase domain (exons 18-22) of EGFR and also whether EGFR isoforms are expressed in the Ishikawa $\mathrm{H}$ or Hec50co cell lines. Sequence of the EGFR tyrosine kinase domain proved to be wild type in both cell lines. While both cell lines expressed full-length EGFR (isoform A), EGFR and sEGFR (isoform D) were expressed at significantly lower levels in Hec50co cells compared to Ishikawa H cells. Analysis of gene expression following EGF vs. gefitinib treatment (a small molecule EGFR tyrosine kinase inhibitor) was performed. Early growth response 1 , sphingosine kinase 2 , dual specificity phosphatase 6 , and glucocorticoid receptor DNA binding factor 1 are members of a cluster of genes downstream of EGFR that are differentially regulated by treatment with EGF compared to gefitinib in Ishikawa $\mathrm{H}$ cells, but not in Hec50co cells.

Conclusions: Type I Ishikawa $\mathrm{H}$ and type II Hec50co endometrial carcinoma cells both express EGFR and sEGFR, but differ markedly in their responsiveness to the EGFR inhibitor gefitinib. This difference is paralleled by differences in the expression of sEGFR and EGFR, as well as in their transcriptional response following treatment with either EGF or gefitinib. The small cluster of differently regulated genes reported here in these type I vs. type II endometrial cancerderived cell lines may identify candidate biomarkers useful for predicting sensitivity to EGFR blockade.
\end{abstract}

\section{Background}

Endometrial carcinoma is the most common gynecologic malignancy in American women [1-3]. Type I endometrial cancers are generally of endometrioid subtype, well differentiated, express estrogen and progesterone receptors (ER and PR), and develop in a setting of estrogen excess unopposed by the differentiating effects of progesterone $[4,5]$. Ishikawa $\mathrm{H}$, a cell line derived from a moderately differentiated endometrioid type I adenocarcinoma [6], is hormone receptor positive and forms rudimentary glandular structures in culture $[7,8]$. In contrast, type II

\footnotetext{
* Correspondence: kimberly-leslie@uiowa.edu

1 The Reproductive Molecular Biology Laboratory, Division of Maternal-Fetal Medicine, Departments of Obstetrics and Gynecology, Biochemistry and Molecular Biology, and Biomedical Sciences, University of New Mexico Health Sciences Center, 2211 Lomas Boulevard Northeast, MSC 10 5580, Albuquerque, NM 87131, USA

Full list of author information is available at the end of the article
}

endometrial cancers include clear cell, serous, and poorly differentiated endometrioid subtypes, are poorly differentiated and result in more aggressive lesions $[4,5]$. Type II tumors are typically resistant to hormonal growth regulation because they express less ER and PR. Hec50co cells were derived from a metastatic type II endometrial cancer and sub-differentiate into a serous subtype in xenografted animal models [9]. Hec50co cells are poorly differentiated in culture and do not express appreciable levels of ER or PR [6].

No effective treatment is available for persistent or recurrent endometrial cancer. New therapies using the rationale that cancer cells express or amplify certain signaling proteins, such as the epidermal growth factor receptor (EGFR) family of tyrosine kinase receptors, are under investigation, as described below. 
EGFR is the prototypic member of the ErbB/HER receptor tyrosine kinase family and binds to multiple ligands including EGF, transforming growth factor alpha, and amphiregulin. EGFR plays a crucial role in cellular functions implicated in cancer development [10], and has been shown to be expressed in a large percentage of endometrial tumors [11]. We previously investigated the expression of EGFR and identified its downstream signaling cascades in both Ishikawa $\mathrm{H}$ and Hec50co cells [12]. Tyrosine kinase inhibitors block EGFR autophosphorylation in both cell lines in vitro [12]. However, the well-differentiated Ishikawa $\mathrm{H}$ cell line responds more robustly to EGFR activation and is more sensitive to receptor inhibition compared to Hec50co cells, which are relatively resistant. Specifically, fewer signaling intermediates are activated or blocked downstream of EGFR in Hec50co cells compared to Ishikawa H cells [12]. Also, cell cycle regulatory events in response to the EGFR tyrosine kinase inhibitor gefitinib are blunted in Hec50co cells compared to Ishikawa $\mathrm{H}$ cells [13]. The reason these poorly differentiated cells do not respond as well to inhibition of EGFR activity is an interesting question that may have bearing on resistance to tyrosine kinase inhibitors in the clinical setting.

Human EGFR is encoded by two transcripts of $10.5 \mathrm{~kb}$ and $5.8 \mathrm{~kb}$ (isoform A) both of which arise from a single promoter region/gene on chromosome 7 [14]; the protein product arising from these two transcripts is identical. In addition to these two transcripts which encode the fulllength EGFR isoform, three alternative transcripts of 1.8, 2.4 , and $3.0 \mathrm{~kb}$, also are derived from the EGFR gene and encode isoforms $C, B$, and $D$, respectively $[15,16]$. While the $1.8 \mathrm{~kb}$ transcript results from read-through of an exon (10) intron boundary, the 2.4 and $3.0 \mathrm{~kb}$ transcripts, encoding isoforms $\mathrm{B}$ and $\mathrm{D}$ transcripts diverge from fulllength EGFR by incorporating alternate exons $15 \mathrm{~A}$ or 15B. Exon 15A encodes a unique carboxy-terminal serine; exon $15 \mathrm{~B}$ encodes an alternative 78 -amino acid $\mathrm{C}$ terminal sequence (isoform D). Both of these alternately spliced transcripts also encode alternative stop codons as well as unique 3' untranslated regions (UTR) including consensus polyadenylation sites (see Figure 1). While the $2.4 \mathrm{~kb}$ isoform $\mathrm{B}$ and its protein product have not been well studied, the $3.0 \mathrm{~kb}$ isoform D transcript encodes a 90/110 kDa EGFR isoform that is associated with the cell membrane through an unidentified mechanism [17] and also can be detected in human serum $[18,19]$. These soluble receptor isoforms resemble the avian secreted sEGFR isoform, which has been shown to bind to ligand and to inhibit ligand-dependent, anchorage-independent growth of primary fibroblasts [15,20]. sEGFR/sHER receptors also have been reported to modulate EGFR/ HER tyrosine kinase activity [21,22]. The $1.8 \mathrm{~kb}$ isoform $\mathrm{C}$ transcript codes for a secreted $60 / 80 \mathrm{kDa}$ soluble EGFR protein that contains only subdomains I, II, and half of subdomain III of the EGFR extracellular region followed by a unique carboxy-terminal Leu-Ser and 3' UTR (Figure 1).

The tyrosine kinase inhibitor gefitinib (Iressa, ZD1839) binds to the ATP binding site of the EGFR kinase domain with a higher affinity than does ATP itself [23]. Heterozygous somatic mutations of the EGFR tyrosine kinase domain (exons 18-21) have been correlated with a positive response to gefitinib [24,25]. These missense (G719S/ $\mathrm{C}$ and L858R) and deletion mutations (in the region spanning codons 746-759) are located in exons 18 through 21 of EGFR and appear to confer tumor susceptibility to gefitinib [24,25]. It has been hypothesized that such mutations stabilize the interaction of EGFR with ATP or gefitinib thereby resulting in an increase in both ligand activation and inhibitor de-activation [24]. These mutations are distinct from the variant EGFRvIII, discovered in glioma and metastatic breast cancer, where mutant receptors maintain constitutively active, ligand-independent receptor activity; moreover, these latter extracellular domain EGFR mutants do not interfere with the ability of the receptor tyrosine kinase domain to bind to gefitinib [24].

Here, we have sequenced the tyrosine kinase domain (exon 18-22) of EGFR and also have determined the expression of these EGFR isoforms in the two endometrial carcinoma cell lines described above. In addition, we have evaluated the effects of gefitinib or EGF on gene expression to better understand how these two cell lines respond to treatment. We hypothesized that Ishikawa $\mathrm{H}$ cells, previously found to be more responsive to EGFR modulation with respect to signaling and cell cycle inhibition, would express functional EGFR and show a robust transcriptional response to EGF $[12,13]$. By contrast, we hypothesized that Hec50co cells, previously found to be more resistant to EGFR modulation with respect to signaling [12] and cell cycle inhibition [13], might differentially express EGFR or its related isoforms, and that these expression patterns may predict a blunted transcriptional response to EGF as well as to gefitinib. The results of these pre-clinical studies contribute to our understanding of the distinguishing cellular characteristics that control drug performance in two well-characterized models of endometrial cancer.

\section{Methods}

\section{Drugs and chemicals}

EGF was purchased from Invitrogen (Carlsbad, CA). Gefitinib (Iressa, ZD1839) was provided by AstraZeneca (Wilmington, DE and Cheshire, UK). The drug was dissolved in dimethyl sulfoxide (DMSO) for all in vitro studies. 


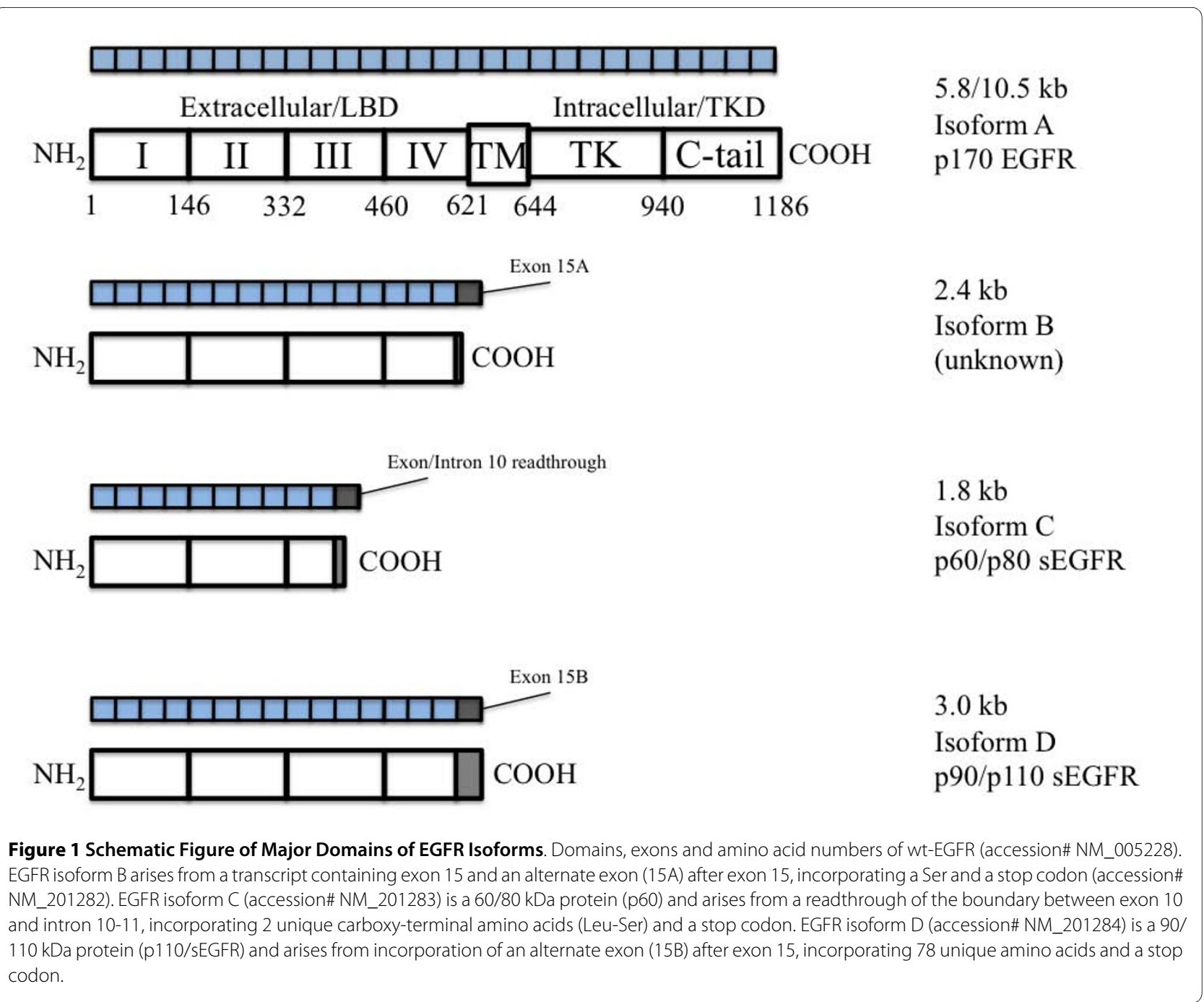

\section{Cells and culture conditions}

Ishikawa $\mathrm{H}$ and Hec50co cells were provided by Dr. E. Gurpide, New York University, and were cultured in DMEM media (Sigma-Aldrich Inc., St. Louis, MO) supplemented with $10 \%$ fetal bovine serum substitute (FetalPlex, Gemini Bio-Products, Woodland, CA), $2 \mathrm{mM} \mathrm{L-}$ Glutamine and $1 \times$ antibiotic-antimycotic solution (GIBCO, Grand Island, NY). Cells were incubated either with $0.1 \%$ DMSO (vehicle), $1 \mu \mathrm{M}$ of gefitinib, or with 30 $\mathrm{ng} / \mathrm{ml}$ EGF for 12 and $24 \mathrm{~h}$ before harvesting for gene array or immunoblot studies as described below.

\section{RNA isolation and microarray hybridization}

Ishikawa $\mathrm{H}$ and $\mathrm{Hec} 50 \mathrm{co}$ cells were cultured and treated as described above. Cells were harvested by scraping, and the pellets were washed twice with phosphate buffered saline (PBS). Total RNA was prepared from the cell pellets according to the manufacturer's protocol using RNeasy spin columns (Qiagen Corp, Valencia, CA). RNA quality was checked using the Agilent 2100 Bioanalyzer
(Agilent Technologies, Foster City, CA). All microarray procedures were performed using the human Affymetrix $^{\mathrm{mt}}$ HG-U133 plus 2.0 chips (Santa Clara, CA). Procedures for the chip preparation and $\mathrm{cDNA} / \mathrm{cRNA}$ synthesis were performed according to instructions from the manufacturer's manual, version 701025 Rev.5. Briefly, $5 \mu \mathrm{g}$ of total RNA was used to generate double-stranded cDNA using an oligo dT-primer containing the T7 RNA polymerase promoter site and the One-Cycle Target Labeling Kit. cDNA was purified via column purification using the GeneChip Sample Cleanup Module, and biotinylated cRNA was synthesized by in vitro transcription using the GeneChip IVT Labeling kit. Biotin labeled cRNA was purified (GeneChip Sample Cleanup Module), and the absorbance was measured at $260 \mathrm{~nm}$ to determine yield (Nanodrop spectrophotometer). Twenty $\mu \mathrm{g}$ of the labeled cRNA was fragmented; the quality of the purified cRNA and the fragmented cRNA was assessed using the Agilent 2100 Bioanalyzer and the RNA 6000 Nano LabChip kit. The labeled fragmented cRNA was hybrid- 
ized to Affymetrix GeneChipHGU133 Plus 2.0 arrays for $16 \mathrm{~h}$ at $45^{\circ} \mathrm{C}$ following the Affymetrix protocol specific to this array type. The washing and staining steps were performed on the Affymetrix 450 fluidics station according to the antibody amplification protocol (Fluidics script: EukGE-WS2v5). The GeneChips were scanned using the Affymetrix GeneChip Scanner 3000 (a wide-field, epifluorescent near-confocal microscope with a patented flying objective).

\section{Real time PCR (qPCR)}

Synthesis of cDNA from total RNA was performed using the High-Capacity cDNA Archive Kit from Applied Biosystems, part number 4322171 (Foster City, CA). One mg of total RNA was converted to cDNA in a $\mu 1 \mathrm{ml} 10 \times$ Reverse Transcription Buffer, $0.4 \mu \mathrm{l} 25 \times$ dNTPs, $\mu 1.0 \mathrm{ml}$ $10 \times$ random primers, $0.5 \mu \mathrm{l} \mathrm{MultiScribe}{ }^{\mathrm{mm}}$ reverse transcriptase, $50 \mathrm{U} / \mu \mathrm{l}$ and $7.1 \mathrm{ml}$ nuclease-free water. The reactions were incubated for $10 \mathrm{~min}$ at $25^{\circ} \mathrm{C}$ followed by $120 \mathrm{~min}$ at $37^{\circ} \mathrm{C}$. Singleplex real time PCR was performed in 384 well format using the Applied Biosystems $7900 \mathrm{HT}$. Reactions were prepared in $10 \mathrm{ml}$ volumes containing 10 ng cDNA, $0.5 \mathrm{ml}$ of the 20x Target Assay Mix or endogenous control, and $5.0 \mu \mathrm{l} 2 \times$ TaqMan Universal Master Mix. Relative quantification was obtained using the Comparative $\mathrm{C}_{\mathrm{t}}$ method. This involves comparing the $\mathrm{C}_{\mathrm{t}}$ values of the samples of interest with a control or calibrator such as a non-treated sample or RNA from normal tissue. We used untreated samples as calibrators. The $C_{t}$ values of both the calibrator and the samples of interest were normalized to an appropriate endogenous housekeeping gene (18S).

\section{Reverse transcriptase polymerase chain reaction (RT-PCR)}

First strand synthesis was performed according to the instructions provided by Invitrogen ${ }^{\mathrm{mm}}$ Life Technologies (Carlsbad, CA). For these studies, $1.0 \mu \mathrm{g}$ of total RNA was used to generate single-stranded cDNA via first strand synthesis using SuperScript ${ }^{\text {tw }}$ III in the presence of oligo$(\mathrm{dT})_{20}$ primer and dNTP's. The mixture was heated to $65^{\circ} \mathrm{C}$ for $5 \mathrm{~min}$ and placed on ice for at least $1 \mathrm{~min}$. First Strand Buffer, dithiothreitol and SuperScript III were added per the protocol directions and incubated for $1 \mathrm{~h}$ at $55^{\circ} \mathrm{C}$ followed by inactivation by heating at $70^{\circ} \mathrm{C}$ for 15 min. PCR was performed according to the instructions provided by Qiagen, Inc (Valencia, CA) for their HotStarTaq Master Mix product. A total of 100 ng of cDNA was added to the reaction as a template along with the appropriate primers and the PCR master mix. An annealing temperature of $59^{\circ} \mathrm{C}$ was used, and PCR was performed over 35 cycles. Equal amounts of the products were separated by agarose gel electrophoresis, and a size marker was included for molecular weight determination.

\section{Immunoblot analysis of EGFR isoforms}

Near-confluent cultures of Ishikawa $\mathrm{H}$ and Hec50co cells were rinsed $3 \times$ with ice-cold PBS and harvested by scraping. Cells were solubilized with boiling SDS-lysis solution (2.5\% SDS, $0.5 \%$ NP-40, 0.5\% deoxycholate) for five minutes. Following solubilization, lysates were diluted 1:9 with $50 \mathrm{mM}$ Tris- $\mathrm{HCl}, \mathrm{pH}$ 7.4, $190 \mathrm{mM} \mathrm{NaCl}, 6 \mathrm{mM}$ EDTA, 2.5\% Triton X-100, and protease inhibitors $(2 \mathrm{mM}$ PMSF, $1 \mathrm{mg} / \mathrm{ml}$ aprotinin, pepstatin, and leupeptin). Cell lysate protein concentration was quantitated by Bio-Rad DC assay.

$\mathrm{CHO} / \mathrm{EGFR}$ and CHO/sEGFR [26] lysates were used as positive controls for EGFR and sEGFR expression, respectively. Samples were loaded onto $7.5 \%$ acrylamide, $1.5 \mathrm{~mm}$-thick Hoeffer slab gels and electrophoresed for 4 hours at $30 \mathrm{~mA}$ (along with Bio-Rad Precision Plus MW markers), followed by transfer to PVDF membrane by semi-dry electroblotting (418 mA for $30 \mathrm{~min}$ ). The membrane was blocked for one hour with $5 \%$ non-fat dry milk in $10 \mathrm{mM}$ Tris- $\mathrm{HCl}, \mathrm{pH} 7.4,150 \mathrm{mM} \mathrm{NaCl}$ (TBS), and rinsed $6 \times$ for 5 min with wash buffer (TBS plus $0.1 \%$ Tween-20). The membrane was then successively probed with antibody directed against $\beta$-tubulin (Cell Signaling Technology, Danvers, MA, 1:500) and EGFR (sc-03, Santa Cruz Biotechnology, Santa Cruz, CA, 1:500) or sEGFR (1:4000) [26] in TBS plus $0.1 \%$ bovine serum albumin (BSA) overnight, followed by $6 \times$ rinses with wash buffer for 10 min each. The sEGFR-specific antibody is directed against the unique carboxy-terminal sequence of the 3.0 kb sEGFR gene product [27], whereas the sc-03 antiEGFR antibody is directed against the EGFR intracellular domain. Membranes were then incubated with secondary antibody (goat anti-rabbit, 1:4000, Pierce) in TBS with $0.1 \%$ BSA for one hour followed by $6 \times$ rinses with wash buffer for 10 min each. Immune complexes were detected by enhanced chemiluminescence (Supersignal West Femto, Pierce).

\section{Sequencing exons 18-22 of EGFR}

cDNA was generated as described above using primers to query each EGFR subdomain (Figure 2). PCR was performed to generate templates for sequencing (standard PCR protocol, $\mathrm{T}_{\mathrm{m}}$ of $59^{\circ} \mathrm{C}$ ). Samples were sequenced at the DNA Research Services Core Laboratory of the University of New Mexico (UNM) using an ABI 377 genetic analyzer, capillary electrophoresis and $\mathrm{ABI}$ big dye terminator ready reaction kits (Applied Biosystems, Carlsbad, CA). The automated instrument system performs electrophoretic separation and spectral detection of dyelabeled DNA fragments to determine base sequence, fragment size, or relative quantity. Sequencing reactions are performed with fluorescent labels: four different dyes identify the A, C, G, and T extension reactions. Primers 


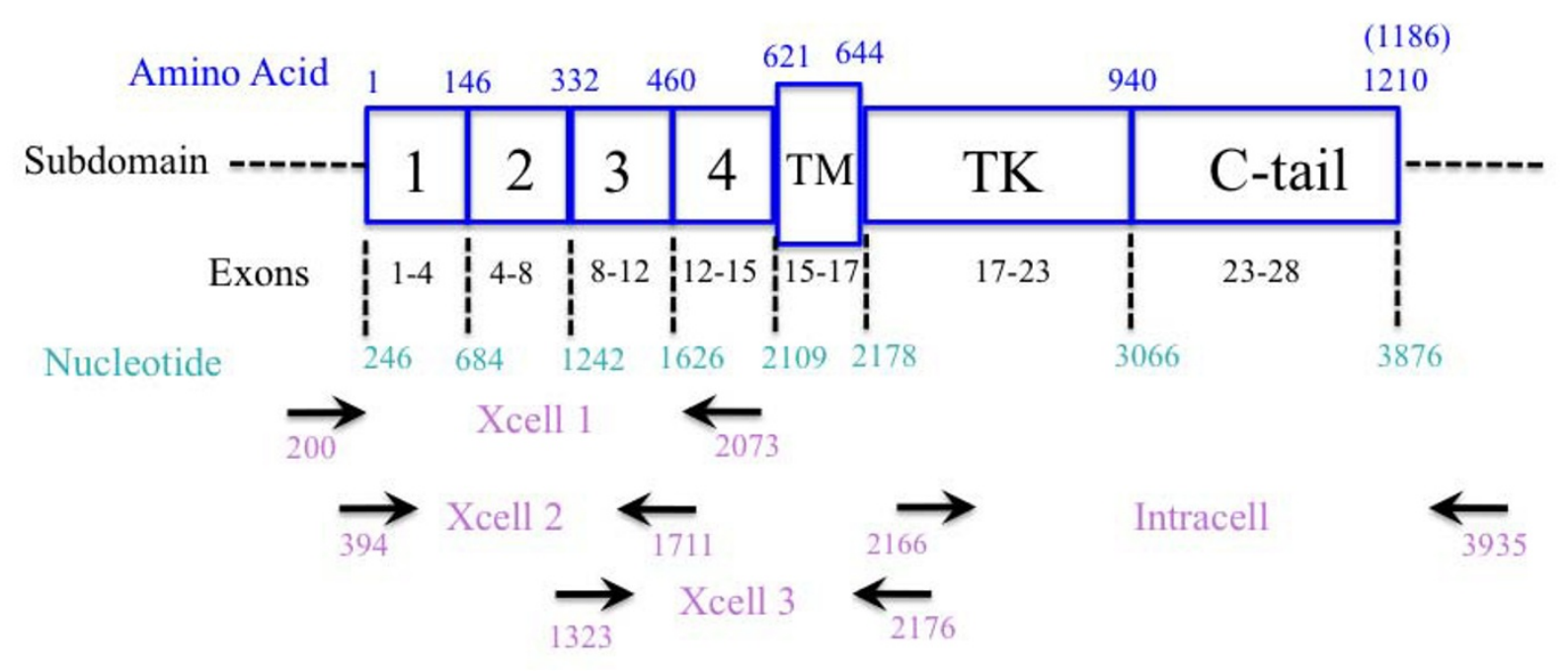

Figure 2 Schematic Figure of Wild Type EGFR Domains and Subdomains. This figure shows the number of exons, amino acids, and nucleotides in each domain. Arrows correspond to selected primers used to identify wild type EGFR and EGFR isoforms. Numbers below the arrows match the location of the primers on EGFR RNA sequence (accession\#NM_005228). Names between arrow pairs correspond to the name of the primer set; Xcell and Intracell specify sequences encoding the extracellular and intracellular domains of EGFR (see Table 1).

used for sequencing EGFR (exon 18-22) are presented in Table 1.

\section{Analytical approaches and data interpretation}

We analyzed the effects of EGF and gefitinib on gene expression in Ishikawa $\mathrm{H}$ and Hec50co cells at $12 \mathrm{~h}$ and $24 \mathrm{~h}$ normalized against specific controls. Two separate experiments were run for each cell line, treatment, and time point. Silicon Genetics' GeneSpring version 7.2 (Palo Alto, CA) was used to filter data using a fluorescent-threshold cutoff and a 2 -fold differential cutoff. Two different normalizations were employed: median-normalization and normalization to specific samples, depending on the comparisons being examined. Data from the two cell lines, Ishikawa $\mathrm{H}$ and Hec50co, were further compared using Venn diagrams. In addition, we employed Ingenuity ${ }^{\mathrm{m}}$ software (Redwood City, CA) to generate common networks between linked genes with analytical changes of 2 -fold or more [28].

\section{Results}

\section{EGFR sequencing in Ishikawa $\mathrm{H}$ and $\mathrm{Hec} 50$ co cells}

Exons 18-22 of the tyrosine domain of EGFR of Ishikawa $\mathrm{H}$ and Hec50co cells were sequenced (Figure 3). PCR products were detected on a DNA agarose gel (Figure 3A) and were found to be the expected size (540 bp). No mutations in the tyrosine kinase domain of EGFR (exons 18-22) were observed in either cell line at the amino acid level. Two conservative single nucleotide polymorphisms were identified that did not change the amino acid sequence (data not shown); therefore, we conclude that the EGFR tyrosine kinase domains are wild type in both cell lines.

\section{EGFR isoforms in Ishikawa $\mathrm{H}$ and Hec50co cells}

Detection of EGFR isoforms in Ishikawa $\mathrm{H}$ and Hec50co cells was conducted initially by RT-PCR. We designed multiple primer sets specific for the EGFR extracellular and intracellular domains (Figure 2). In addition, primers that span regions of the internally-deleted variant and the soluble isoforms were included (Table 1; see Materials and Methods). The products of these reactions (Figure 3B) were expected to identify the expression of EGFR wild type and soluble isoforms (Figure 1) as well as EGFRvIII. PCR products were analyzed by agarose gel electrophoresis to confirm size and abundance, using primer templates as negative controls (Figure 3B). As determined from the primer set locations and band sizes on agarose gels, EGFRvIII expression was not detected. Using semi-quantitative methods, we also detected the message for the $1.8 \mathrm{~kb}$ sEGFR isoform (isoform $\mathrm{C}$ ) at comparable levels in both Ishikawa $\mathrm{H}$ and Hec50co cells (Figure 3B). By these same methods the $3.0 \mathrm{~kb}$ sEGFR transcript (isoform D, Figure $3 \mathrm{~B}$ ) appeared to be expressed at higher levels in the Hec50co cells relative to the Ishikawa $\mathrm{H}$ cells (isoform $\mathrm{D}$ transcript is just detectable in Ishikawa cells). The $2.4 \mathrm{~kb}$ isoform (B) was not observed in either cell line. However, RT-PCR is not quantitative, and when immunoblot analysis was performed to assess isoform D protein expression (Figure 4), 
Table 1: Primer Sets for Amplification of EGFR Isoforms and Mutants.

\begin{tabular}{|c|c|c|}
\hline Primer set name & Sequence & Expected band size (bp) \\
\hline EGFR forward extracellular 1 (Xcell 1) & ccagtattgatcgggagagc & 1873 \\
\hline EGFR reverse extracellular 1 (Xcell 1) & acaacaccctggtctggaag & \\
\hline EGFR forward extracellular 2 (Xcell 2) & agcctccagaggatgttcaa & 1318 \\
\hline EGFR reverse extracellular 2 (Xcell 2) & tggttttctgaccggaggt & \\
\hline EGFR forward extracellular 3 (Xcell 3) & caaaaactgcacctccatca & 854 \\
\hline EGFR reverse extracellular 3 (Xcell 3) & ggatcttaggecccattcgtt & \\
\hline EGFR forward intracellular (Intracell) & cctaagatcccgtccatcg & 1769 \\
\hline EGFR reverse intracellular (Intracell) & ttggtcctgggtatcgaaag & \\
\hline EGFR isoform $B$ forward & aacaacacctggtctggaa & 160 \\
\hline EGFR isoform $B$ reverse & tgaagcaaagggagaaattga & \\
\hline EGFR isoform C forward & ggatattctgaaaaccgtaaaggaaa & 96 \\
\hline EGFR isoform $C$ reverse & cgaaaagttctctctaaaacactgatt & \\
\hline EGFR isoform $D$ forward & ccagtgtgcccactacattg & 221 \\
\hline EGFR isoform $D$ reverse & cgctgccatcattactttga & \\
\hline Sequencing primers (exon 18-22) forward & ccaaccaagctctcttgagg & 540 \\
\hline Sequencing primers (exon $18-22$ ) reverse & tgataggcactttgcctcct & \\
\hline
\end{tabular}

more sEGFR protein was detected in Ishikawa $\mathrm{H}$ cells using an antibody specific for the unique carboxy-terminal sequence of isoform D [26] than was detected in Hec50co cells. Both cell lines expressed wild type EGFR with higher levels in Ishikawa H cells (Figure 4).

\section{Effects of EGF and gefitinib on gene expression in Ishikawa $\mathrm{H}$ cells}

Ishikawa $\mathrm{H}$ cells were incubated with either $30 \mathrm{ng} / \mathrm{ml}$ EGF or $1 \mu \mathrm{M}$ gefitinib for 12 and $24 \mathrm{~h}$. Cells were harvested, and total RNA was isolated for microarray studies using human Affymetrix ${ }^{\mathrm{TM}}$ HG-U133 plus 2.0 chips. The expression of 134 and 150 genes was altered 2-fold or more at 12 and $24 \mathrm{~h}$, respectively, after exposure to EGF. Forty-four genes were regulated both at the 12 and $24 \mathrm{~h}$ time points (Additional File 1, Table S1). The expression of 132 and 61 genes was altered at 12 and $24 \mathrm{~h}$, respectively, after gefitinib treatment. Twenty-five genes were found to be regulated at both the 12 and $24 \mathrm{~h}$ time points (Additional File 1, Table S1). While most genes were induced or down-regulated similarly at 12 and $24 \mathrm{~h}$, some genes were differentially regulated. For example, the expression of Splicing Factor 4 (SF4) was decreased by 0.472 fold at $12 \mathrm{~h}$ and increased by 3.639 fold at $24 \mathrm{~h}$ in response to EGF in Ishikawa $\mathrm{H}$ cells. Sphingosine kinase 2 (SphK2) and protein inhibitor of activated STAT (PIASy) showed a similar pattern in response to gefitinib: decreased at $12 \mathrm{~h}$ but increased at $24 \mathrm{~h}$. For those genes regulated by both EGF and gefitinib, the majority demonstrated an induction by one treatment and a down-regu- 


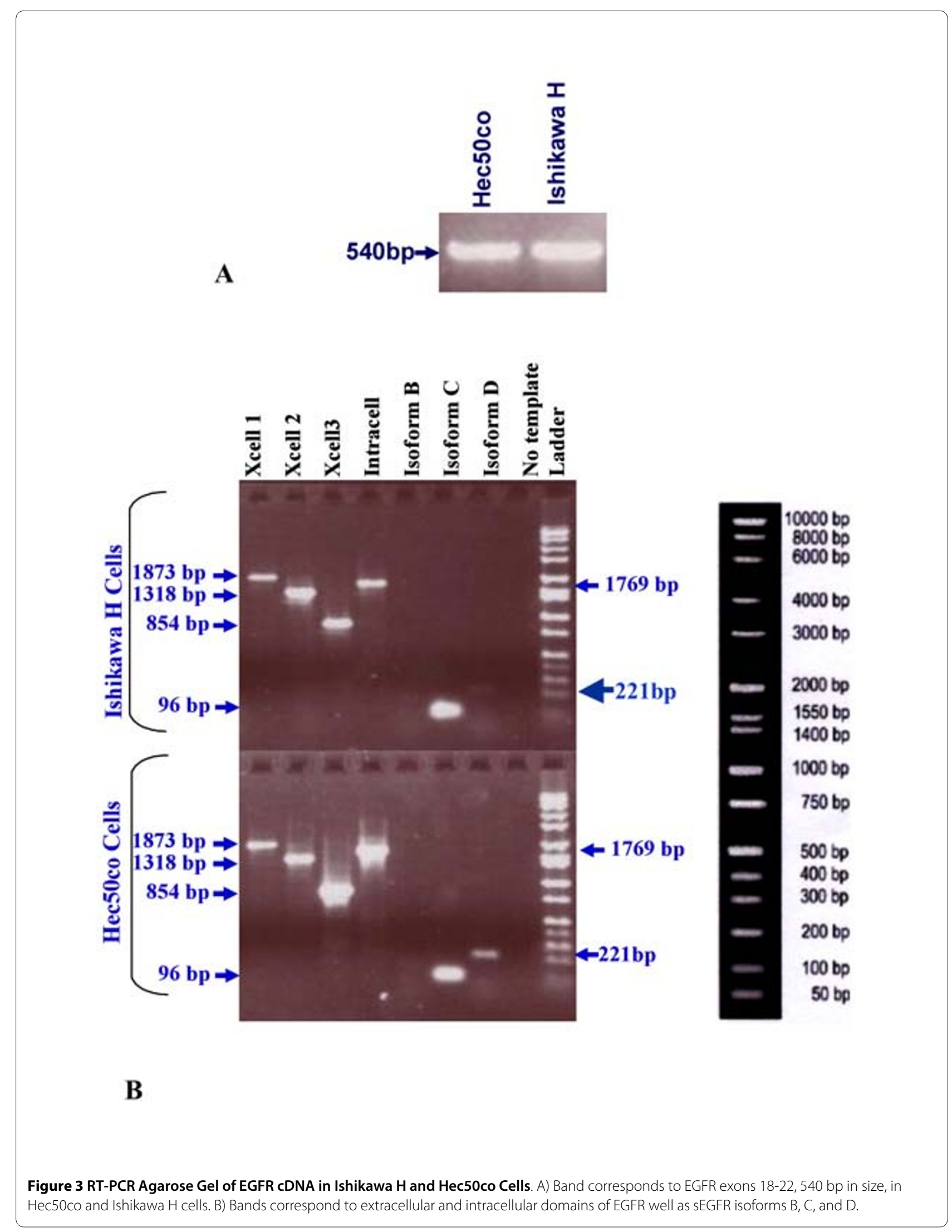




\section{Effects of EGF and gefitinib on gene expression in Hec50co cells}

Hec50co cells were incubated with either $30 \mathrm{ng} / \mathrm{ml}$ EGF or $1 \mu \mathrm{M}$ gefitinib for 12 and $24 \mathrm{~h}$. Cells were harvested, and total RNA was isolated as above. After excluding the hypothetical gene products and the ESTs, the expression of 35 and 58 genes was altered in response to EGF at 12 and $24 \mathrm{~h}$ compared to untreated control cells. Three genes (fibroblast growth factor receptor 2, stanniocalcin 1 , and kinesin family member $26 \mathrm{~A}$ ) were found to be regulated at both the 12 and $24 \mathrm{~h}$ time points in response to EGF. The expression of 14 and 59 genes was altered in response to gefitinib after 12 and $24 \mathrm{~h}$, respectively, in comparison to untreated controls. One gene, calcium homeostasis endoplasmic reticulum protein, was found to be regulated at both 12 and 24 h (Additional File 1, Table S1).

\section{Effects of EGF and gefitinib on gene expression in Ishikawa $\mathrm{H}$ vs. Hec50co cells}

Gene expression in response to EGF and gefitinib was further analyzed to determine commonly regulated genes. Two genes, EGR1 (up-regulated) and polycystic kidney disease 1-like (down-regulated), were commonly regulated in both Ishikawa $\mathrm{H}$ and Hec50co cells in response to EGF at $12 \mathrm{~h}$ (Additional File 1, Table S1). Three down-regulated genes (papilin-proteoglycan-like sulfated glycoprotein, fibroblast growth factor receptor 2, and cadherin 16, KSP-cadherin) were similarly regulated in both cell lines in response to EGF at $24 \mathrm{~h}$. One gene, glucocorticoid receptor DNA binding factor (GRLF1), was found to be differentially controlled by gefitinib (down-regulated in Ishikawa $\mathrm{H}$ and up-regulated in Hec50co cells) at $12 \mathrm{~h}$. SphK2 and PIASy were two common genes (both induced) in Ishikawa $\mathrm{H}$ and Hec50co cells after $24 \mathrm{~h}$ of gefitinib treatment based on these gene array data.

\section{Real time PCR confirms changes in gene expression for selected genes}

Findings from the array experiments were confirmed for four genes by qPCR in Ishikawa $\mathrm{H}$ cells (Figure 5) and Hec50co cells (Figure 6). These four transcripts were chosen from diverse functional categories. We were interested in common genes between Ishikawa $\mathrm{H}$ and Hec50co cells that would comprise a core set of transcripts downstream of EGF/EGFR. We identified two genes in this category for confirmation: EGR1, that was induced by EGF at $12 \mathrm{~h}$ (3.365 fold in Ishikawa $\mathrm{H}$ and 2.442 fold in Hec50co cells); and glucocorticoid receptor DNA binding factor 1 (GRLF1), that was down-regulated by gefitinib at $12 \mathrm{~h}$ in Ishikawa $\mathrm{H}$ cells ( 0.483 fold) and induced in Hec50co cells (2.73 fold). In addition, SphK2 was of special interest because it was differentially 
expressed in response to gefitinib over time in Ishikawa $\mathrm{H}$ cells (down-regulated at $12 \mathrm{~h}$ and induced at $24 \mathrm{~h}$ ). DUSP6 is also a gene downstream of EGFR signaling pathways. DUSP6 was induced by EGF and down-regulated by gefitinib treatment at $12 \mathrm{~h}$ and $24 \mathrm{~h}$ in Ishikawa $\mathrm{H}$ cells (Additional File 1, Table S1).

\section{Gene networks}

Analyzing the Affymetrix expression array data using Venn diagrams and Ingenuity ${ }^{\mathrm{TM}}$ networks provided additional insight into the transcriptional response of Ishikawa $\mathrm{H}$ and Hec50co cells to EGF and gefitinib. Ishikawa $\mathrm{H}$ cells are clearly more responsive to gefitinib, but Hec50co cells demonstrate similarities as well as interesting differences, including the induction of a group of pro-proliferative and compensatory factors at $24 \mathrm{~h}$. Such factors may be markers of resistance to gefitinib worthy of future validation. These data are provided in

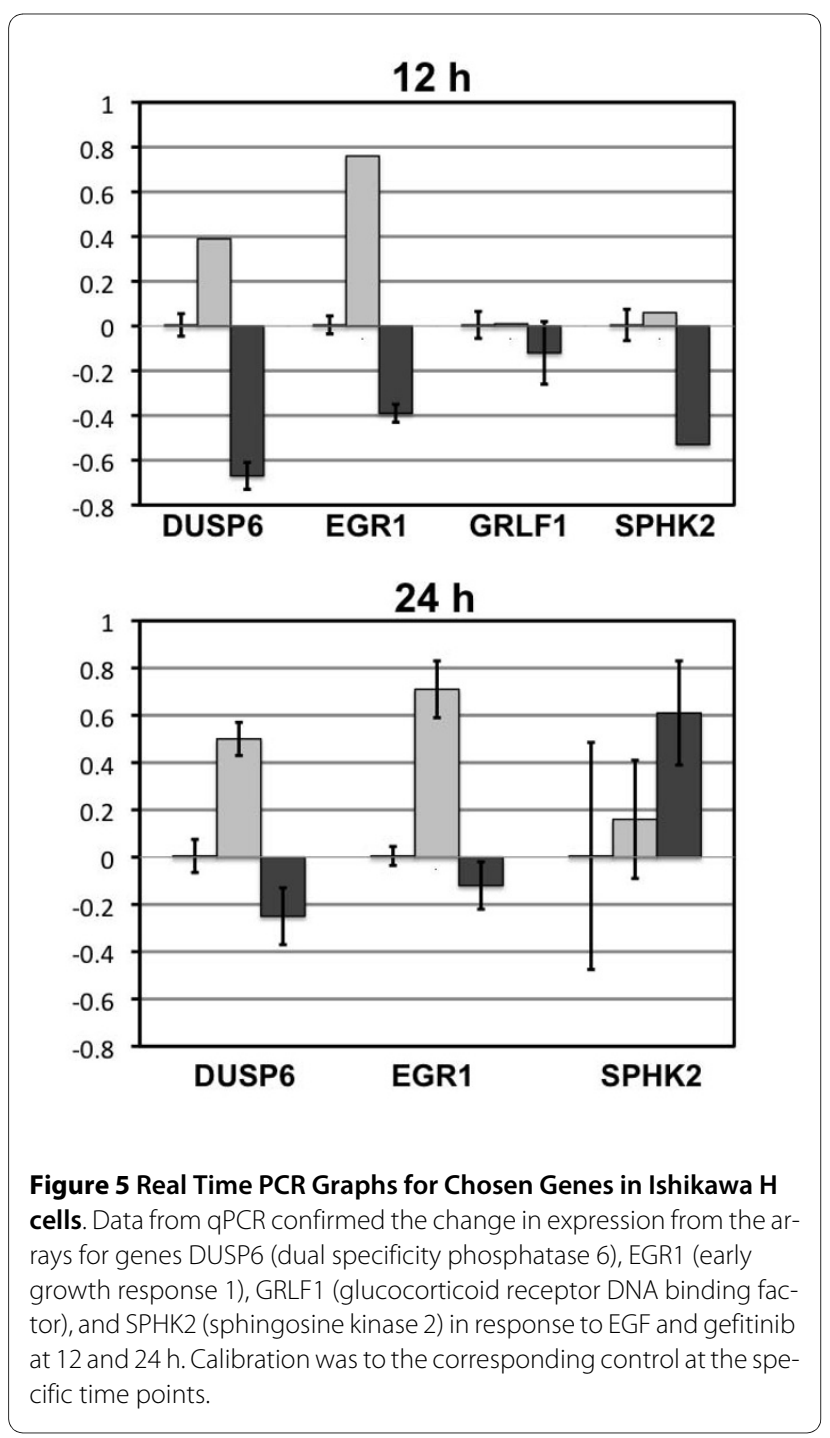

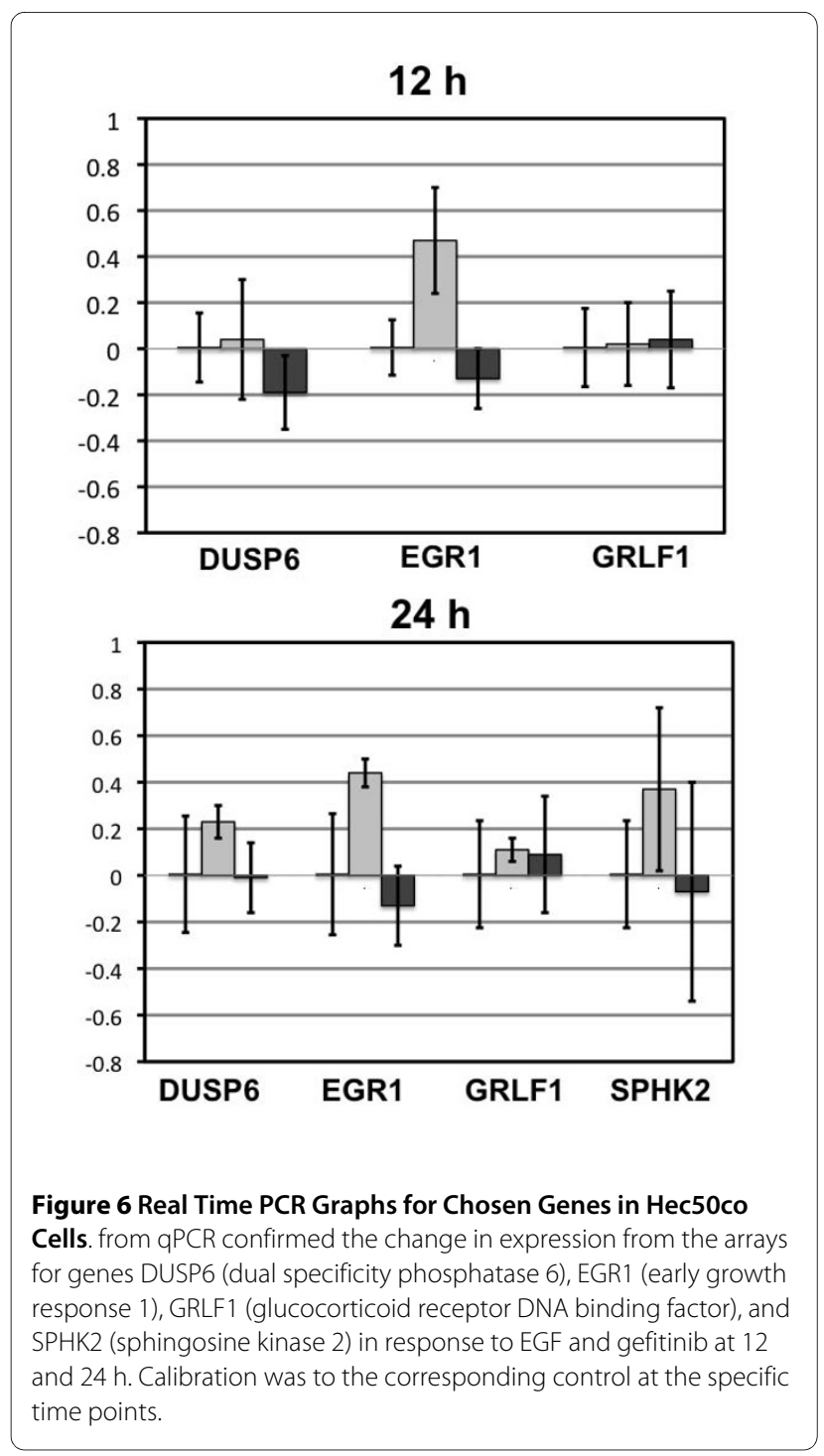

the Additional Files of this manuscript and discussed below.

\section{Discussion}

To evaluate the potential therapeutic effects of tyrosine kinase inhibitors in the treatment of endometrial cancer, we previously have characterized the EGFR pathway in endometrial cancer cells at the signaling level [12], with respect to cell cycle [13], and now at the genomic level. First we sequenced the tyrosine kinase domain of EGFR (exon 18-22) and identified the isoforms present in Ishikawa $\mathrm{H}$ cells (moderately differentiated) and Hec50co cells (poorly differentiated). In both cell types, no mutations were detected in EGFR that modify the amino acid sequence in the ATP binding pocket. Transcripts encoding the alternate EGFR isoforms, $C$ and $D$, were detected in both cell lines. Immunoblot analysis with an antibody specific for sEGFR isoform D demonstrated that Ishikawa 
$\mathrm{H}$ cells express more isoform D compared to Hec50co cells (Figure 4). It is unclear whether this finding relates to the relative sensitivity of Ishikawa $\mathrm{H}$ cells to gefitinib compared to more resistant Hec50co cells. However, decreased serum levels of this same sEGFR isoform have been reported in both ovarian $[18,29]$ as well as endometrial cancer patients (preliminary findings, Leslie et al., unpublished results, and ASCO, 2009), and higher serum sEGFR concentrations have been correlated with responsiveness to gefitinib in both lung and colon cancer patients $[30,31]$. Since serum sEGFR arises from the isoform $\mathrm{D}$ transcript, there may be a link between these observations, and further study of the function of this sEGFR isoform in endometrial cancer is clearly warranted. In this regard, serum sEGFR concentrations also have been correlated with the female gonadotropin follicle stimulating hormone, as well as with responsiveness to treatment with the aromatase inhibitor letrozole in breast cancer patients [32,33], suggesting a complex relationship between this novel serum biomarker and steroid hormones such as estrogen and progesterone.

Gene expression was also evaluated in response to EGF and gefitinib. The purpose of these studies was to explore the genomic pathways activated or inhibited downstream of EGFR in cells that are model of type I endometrial cancer and somewhat responsive to tyrosine kinase activation or inhibition versus those type II endometrial cancer that are resistant. The most striking observation is the apparent resistance of Hec50co cells to gefitinib at the transcriptional level: the pattern of gene expression was altered for fewer transcripts in response to gefitinib compared to the more robust response observed in Ishikawa $\mathrm{H}$ cells. These data are in agreement with our previous work indicating that gefitinib had little effect on Hec50co signaling pathways as assessed by phosphopeptide mapping [12] and analysis of cell cycle signaling events [13]. Together, these results combined with the genomic data presented here confirm that poorly differentiated Hec50co cells are resistant to gefitinib at multiple points downstream of EGFR signaling. We previously have linked gefitinib resistance in Hec50co cells with expression of the endogenous inhibitor of p53, MDM2, the phospho-activation of which is not fully blocked by gefitinib in this cell line [13]. Gene expression data from the two cell lines was further analyzed using Venn diagrams (Additional File 2, Figure S1). Alterations in the expression pattern of four differentially expressed genes were confirmed by qPCR. Interestingly, EGFR blockade modulates the downstream transcription activity of glucocorticoid receptor, predicting an anti-inflammatory and antiproliferative effect in Ishikawa $\mathrm{H}$ cells.

Another interesting gene product, the dual specificity phosphastase (specific for ERK; DUSP6), was induced by EGF at 12 and $24 \mathrm{~h}$ (2.839 and 2.867 fold, respectively) and down-regulated by gefitinib treatment at $12 \mathrm{~h}$ and 24 $\mathrm{h}(0.288$ and 0.381 fold, respectively) in Ishikawa $\mathrm{H}$ cells (Additional File 1, Table S1). These changes were confirmed by qPCR (Figure 5). Such changes in DUSP6 expression appear to form part of a negative feedback loop where EGF induces DUSP6, which then inhibits ERK signaling downstream of EGFR.

Two other gene products, sphingosine kinase 2 (SphK2) and EGR1, an early response transcription factor, were also differentially regulated in these two cell lines. SphK2 message was down-regulated by gefitinib at $12 \mathrm{~h}(0.445$ fold) and induced by gefitinib at $24 \mathrm{~h}$ (2.172 fold) in Ishikawa $\mathrm{H}$ cells (Additional File 1, Table S1), indicating a potential biphasic effect of gefitinib on apoptosis (inhibited at $12 \mathrm{~h}$, but induced at $24 \mathrm{~h}$ ). EGR1, in contrast, is a central target of EGFR signaling that is induced by receptor activation and inhibited by tyrosine kinase blockade (Figure 5). Further studies may be undertaken to determine whether inhibition of EGR1 expression by tyrosine kinase inhibitors correlates with clinical response in patients; here we identify EGR1 as a potential marker of gefitinib response that warrants future investigation.

The findings from the Venn diagrams and Ingenuity ${ }^{\mathrm{TM}}$ networks, depicted in Additional Files 2, 3, 4, 5, 6, 7, 8, 9 and 10 (Figures S1-S9), show the genes regulated at 12 and $24 \mathrm{~h}$ by EGF or gefitinib in both Ishikawa $\mathrm{H}$ and Hec50co cells in the context of their interacting pathways. Considering the expansive role of EGFR in cellular functions, the genes consistently regulated in these cell lines (Additional File 2, Figure S1) identifies a surprisingly small core set of transcripts which may have utility as markers of response to novel therapeutics targeting the EGF pathway in patients with endometrial cancer.

The gene networks demonstrate that Ishikawa $\mathrm{H}$ cells were robustly responsive to EGF at $12 \mathrm{~h}$ treatment, including the induction of the central gene discussed above, EGR1 (Additional File 3, Figure S2). EGR1 is functionally linked to other genes upregulated by EGF treatment at $12 \mathrm{~h}$, including FOS, SMAD3, FOSL1, FGFR1, MMP1, ETS1, SERPINE1, DUSP6, etc., which constitute a growth-promoting pathway in response to EGF (Additional File 3, Figure S2); of this pathway, EGR1, SMAD3, FOSL1, and MMP1 were also upregulated at $24 \mathrm{~h}$ of EGF treatment (Additional File 4, Figure S3). Of interest, this growth promoting pathway is linked to an immune modulatory transcriptional response, with IL-1 $\beta$, IL-8, TNFRF21, and TNFRSF10A all induced. It is, perhaps, not surprising that proliferation and inflammation pathways are linked responses to EGF in endometrial carcinoma-derived cells, as has been observed in other models of cancer including hepatocellular carcinoma [34].

Consistent with this observation that an EGR1-containing pathway was upregulated by EGF treatment of Ishikawa $\mathrm{H}$ cells, treatment with the EGFR inhibitor gefi- 
tinib dampened EGR1 expression in Ishikawa $\mathrm{H}$ cells at $12 \mathrm{~h}$ (Additional File 5, Figure S4) and $24 \mathrm{~h}$ (Additional File 6, Figure S5), along with concomitant downregulation of expression of downstream genes such as FOSL1. This core group of EGF-responsive genes was regulated in the opposite manner by gefitinib. DUSP4 expression was also inhibited by gefitinib, and may constitute another marker gene of gefitinib response.

EGF/gefitinib-mediated transcriptional regulation in the type II EC cell line Hec50co was generally blunted but shared similarities with those observed in Ishikawa $\mathrm{H}$ cells, as well as some surprising differences. EGF-mediated EGR1 expression was upregulated at $12 \mathrm{~h}$ (Additional File 7, Figure S6), but not by $24 \mathrm{~h}$ (Additional File 8 , Figure S7) in Hec50co cells; gefitinib treatment failed to inhibit EGR1 expression (Additional File 7, Figure S6 and Additional File 8, Figure S7, respectively). Surprisingly, EGF treatment caused a down-regulation of FGFR2 expression in Hec50co cells at both $12 \mathrm{~h}$ and $24 \mathrm{~h}$.

At $12 \mathrm{~h}$ treatment (Additional File 9, Figure S8), gefitinib induced the expression of HDAC5, a growth inhibitory tumor suppressor and pro-apoptotic factor [35], in Hec50co cells, while regulators of cell migration and morphogenesis such as GIT1 and CALD1 were downregulated by gefitinib. Also at $12 \mathrm{~h}$ of gefitinib treatment, APBA2 and RSP2, previously found to be highly expressed in endometrial carcinomas [36] and prostate cancer [37], respectively, were inhibited. However, by 24 $\mathrm{h}$ treatment (Additional File 10, Figure S9), Hec50co cells demonstrated a transcriptional response that may be compensatory to the anti-proliferative effects of gefitinib in that some genes associated with malignant transformation and tumor progression were induced. For example, ENC-1, often over-expressed in some types of leukemia [38], KLF12, a transcription factor associated with progression of gastric cancer [39], and CDC42EP2, a small Rho GTPase binding protein involved in hypoxiainduced angiogenesis [40], were induced by gefitinib at 24 $\mathrm{h}$ treatment. The induction of SMAD5 by gefitinib is also intriguing. SMAD5 has been characterized alternatively as a tumor suppressor or growth promoter, depending on cell context, so its specific function in response to gefitinib will require further study to fully understand.

In summary, the Ingenuity ${ }^{\mathrm{TM}}$ networks suggest several interesting findings. Ishikawa $\mathrm{H}$ cells are relatively responsive at the level of transcription to the growth-promoting effects of EGF and the growth inhibitory effect of gefitinib, as exemplified by the induction or inhibition of expression of a set of core genes including EGR1. Hec50co cells, however, show less of a proliferative response to EGF and an anti-proliferative response to gefitinib, with possible compensatory signaling apparent at $24 \mathrm{~h}$ treatment.

\section{Conclusions}

In summary, to the extent that Ishikawa $\mathrm{H}$ cells model type I tumors, it is predicted that type I but not type II endometrial cancers have the capacity to respond therapeutically to EGFR-targeted tyrosine kinase inhibitors. Yet sequence analysis of hot spots within the tyrosine kinase domain of the EGFR in both type I and type IIderived cell lines revealed no mutations that might result in such differential sensitivity. Hec50co cells do, however, express lower levels of both sEGFR and EGFR, and such differences are consistent with previous reports indicating that serum sEGFR levels may be a useful indicator of responsiveness to gefitinib in other cancers, and also with the observation that serum sEGFR is a useful predictor of overall survival in endometrial cancer patients. In addition, our results suggest that type II endometrial tumors may be more resistant to EGFR-targeted therapies, at least in part, because they lack a genomic response that includes the modulation of the gene products described above in type I-derived endometrial cancer cells. If this hypothesis is correct, the changes in gene expression patterns observed here also may reveal potential biomarkers that warrant further investigation as surrogate biomarkers of responsiveness or resistance to gefitinib.

\section{Additional material}

Additional file 1 Table S1. List of genes regulated by EGF and gefitinib at $12 \mathrm{~h}$ and $24 \mathrm{~h}$ in Ishikawa $\mathrm{H}$ cells versus Hec50co cells.

Additional file $\mathbf{2}$ Figure $\mathbf{S 1}$. Venn diagrams depicting the commonly and differentially regulated transcripts by EGF and gefitinib (Iressa) in Ishikawa $\mathrm{H}$ and Hec50co cells.

Additional file $\mathbf{3}$ Figure $\mathbf{S}$. Ingenuity ${ }^{\mathrm{TM}}$ network depicting the transcriptional pathway most highly regulated in Ishikawa $\mathrm{H}$ cells treated with EGF for $12 \mathrm{~h}$.

Additional file 4 Figure $\mathbf{S} 3$. Ingenuity ${ }^{\mathrm{TM}}$ network depicting the transcrip tional pathway most highly regulated in Ishikawa $\mathrm{H}$ cells treated with EGF for $24 \mathrm{~h}$.

Additional file $\mathbf{5}$ Figure $\mathbf{S 4}$. Ingenuity $\mathrm{y}^{\mathrm{TM}}$ network depicting the transcriptional pathway most highly regulated in Ishikawa $\mathrm{H}$ cells treated with gefitinib (Iressa) for $12 \mathrm{~h}$.

Additional file 6 Figure S5. Ingenuity ${ }^{\mathrm{TM}}$ network depicting the transcriptional pathway most highly regulated in Ishikawa $\mathrm{H}$ cells treated with gefitinib (Iressa) for $24 \mathrm{~h}$.

Additional file $\mathbf{7}$ Figure S6. Ingenuity ${ }^{\mathrm{TM}}$ network depicting the transcriptional pathway most highly regulated in Hec50co cells treated with EGF for $12 \mathrm{~h}$

Additional file 8 Figure S7. Ingenuity ${ }^{\mathrm{TM}}$ network depicting the transcriptional pathway most highly regulated in $\mathrm{Hec} 50$ co cells treated with EGF for $24 \mathrm{~h}$

Additional file 9 Figure S8. Ingenuity ${ }^{\mathrm{TM}}$ network depicting the transcrip tional pathway most highly regulated in $\mathrm{Hec} 50 \mathrm{co}$ cells treated with gefitinib (Iressa) for $12 \mathrm{~h}$.

Additional file $\mathbf{1 0}$ Figure S9. Ingenuity ${ }^{\mathrm{TM}}$ network depicting the transcriptional pathway most highly regulated in $\mathrm{Hec} 50 \mathrm{co}$ cells treated with gefitinib (Iressa) for $24 \mathrm{~h}$.

\section{Competing interests}

The authors declare that they have no competing interests. 


\section{Authors' contributions}

All authors read and approved the final manuscript. LA designed and conducted the studies, carried out corresponding data analyses (other than where indicated below), and drafted the manuscript. GP analyzed the microarray data. MM performed the microarray analysis. JAW participated in study design, carried out the immunoassays, and helped to draft the manuscript. NJM participated in study design, and helped to draft the manuscript. KKL conceived of the study, oversaw its design and the experimental plan and completed the manuscript.

\section{Acknowledgements}

We thank AstraZeneca for providing gefitinib. Support also was provided by the Keck-UNM Genomics Resource (KUGR), Facility of the UNM Cancer Research and Treatment Center, the WM Keck Foundation, and the State of New Mexico. The authors would like to thank Dr. Jill Reiter (Yale University) for technical comments/discussions related to this manuscript and Dr. Suzy Davies for assisting with the review of the manuscript.

This work was supported by NIH grant R01CA99908 to K.K.L. and N.J.M., NIH CA27469, Gynecologic Oncology Group Core Laboratory for Receptors to K.K.L., NIH CA79808 to N.J.M., a Cancer Research Postdoctoral Fellowship from the Ladies Auxiliary to the Veterans of Foreign Wars to J.A.W., a grant from the Elsa U. Pardee Foundation to J.A.W., the Cory Beach Foundation, and donations from Mrs. Shirley Leslie and Dean and Alice Irvin to K.K.L.

\section{Author Details}

1The Reproductive Molecular Biology Laboratory, Division of Maternal-Fetal Medicine, Departments of Obstetrics and Gynecology, Biochemistry and Molecular Biology, and Biomedical Sciences, University of New Mexico Health Sciences Center, 2211 Lomas Boulevard Northeast, MSC10 5580, Albuquerque, NM 87131, USA, 2KUGR Microarray and Genomics Facility, University of New Mexico Health Sciences Center, 2325 Camino de Salud NE, Albuquerque, NM 87131, USA, 3Department of Obstetrics, Gynecology, \& Reproductive Sciences, Yale University School of Medicine, PO Box 208063, 310 Cedar St., New Haven, CT 06520, USA, 4Departments of Pathology, and Pharmacology, Yale University School of Medicine, PO Box 208063, 310 Cedar St., New Haven, CT 06520, USA, 5Department of Obstetrics and Gynecology, Harvard Medical School, Brigham and Women's Hospital, 75 Francis St., Boston, MA 02115, USA, 6 Mind Research Network, 1101 Yale Boulevard NE, Albuquerque, NM 87106, USA and 7 Department of Obstetrics and Gynecology, University of lowa. Hospitals and Clinics, 200 Hawkins Drive, lowa City, IA 52242, USA

Received: 4 August 2009 Accepted: 25 June 2010

Published: 25 June 2010

\section{References}

1. Platz CE, Benda JA: Female genital tract cancer. Cancer 1995, 75:270-294.

2. Rose PG: Endometrial carcinoma. N Engl J Med 1996, 335:640-649.

3. Arnett-Mansfield RL, DeFazio A, Mote PA, Clarke CL: Subnuclear distribution of progesterone receptors $A$ and $B$ in normal and malignant endometrium. J Clin Endocrinol Metab 2004, 89:1429-1442.

4. Sherman ME, Bur ME, Kurman RJ: p53 in endometrial cancer and its putative precursors: evidence for diverse pathways of tumorigenesis. Hum Pathol 1995, 26:1268-1274.

5. Sherman ME, Sturgeon S, Brinton L, Kurman RJ: Endometrial cancer chemoprevention: implications of diverse pathways of carcinogenesis. J Cell Biochem Supp/ 1995, 23:160-164.

6. Albitar L, Pickett G, Morgan M, Davies S, Leslie KK: Models representing type I and type II human endometrial cancers: Ishikawa $\mathrm{H}$ and $\mathrm{Hec50cO}$ cells. Gynecologic oncology 2007, 106:52-64.

7. Leslie KK, Kumar NS, Richer J, Owen G, Takimoto G, Horwitz KB, Lange C: Differential expression of the $A$ and $B$ isoforms of progesterone receptor in human endometrial cancer cells. Only progesterone receptor $B$ is induced by estrogen and associated with strong transcriptional activation. Ann N Y Acad Sci 1997, 828:17-26.

8. Kumar NS, Richer J, Owen G, Litman E, Horwitz KB, Leslie KK: Selective down-regulation of progesterone receptor isoform $B$ in poorly differentiated human endometrial cancer cells: implications for unopposed estrogen action. Cancer Res 1998, 58:1860-1865.

9. Dai D, Albitar L, Nguyen T, Laidler LL, Singh M, Leslie KK: A therapeutic model for advanced endometrial cancer: systemic progestin in combination with local adenoviral-mediated progesterone receptor expression. Mol Cancer Ther 2005, 4:169-175.

10. Herbst RS: Review of epidermal growth factor receptor biology. Int J Radiat Oncol Biol Phys 2004, 59:21-26.

11. Konecny GE, Santos L, Winterhoff B, Hatmal M, Keeney GL, Mariani A, Jones M, Neuper C, Thomas B, Muderspach L, et al:: HER2 gene amplification and EGFR expression in a large cohort of surgically staged patients with nonendometrioid (type II) endometrial cancer. $\mathrm{Br}$ J Cancer 2009, 100:89-95.

12. Albitar $L$, Laidler $L L$, Abdallah $R$, Leslie KK: Regulation of signaling phosphoproteins by epidermal growth factor and Iressa (ZD1839) in human endometrial cancer cells that model type I and II tumors. Mol Cancer Ther 2005, 4:1891-1899.

13. Albitar L, Carter MB, Davies S, Leslie KK: Consequences of the loss of p53, RB1, and PTEN: relationship to gefitinib resistance in endometrial cancer. Gynecologic oncology 2007, 106:94-104.

14. Ishii S, Xu YH, Stratton RH, Roe BA, Merlino GT, Pastan I: Characterization and sequence of the promoter region of the human epidermal growth factor receptor gene. Proc Natl Acad Sci USA 1985, 82:4920-4924.

15. Reiter JL, Maihle NJ: A $1.8 \mathrm{~kb}$ alternative transcript from the human epidermal growth factor receptor gene encodes a truncated form of the receptor. Nucleic Acids Res 1996, 24:4050-4056

16. Reiter JL, Threadgill DW, Eley GD, Strunk KE, Danielsen AJ, Sinclair CS, Pearsall RS, Green PJ, Yee D, Lampland AL, et al:: Comparative genomic sequence analysis and isolation of human and mouse alternative EGFR transcripts encoding truncated receptor isoforms. Genomics 2001, 71:1-20.

17. Reiter $\mathrm{J}$, Maihle NJ: Characterization and expression of novel 60-kDa and 110-kDa EGFR isoforms in human placenta. Ann N Y Acad Sci 2003, 995:39-47.

18. Baron AT, Cora EM, Lafky JM, Boardman CH, Buenafe MC, Rademaker A, Liu D, Fishman DA, Podratz KC, Maihle NJ: Soluble epidermal growth factor receptor (sEGFR/sErbB1) as a potential risk, screening, and diagnostic serum biomarker of epithelial ovarian cancer. Cancer Epidemiol Biomarkers Prev 2003, 12:103-113.

19. Lafky JM, Wilken JA, Baron AT, Maihle NJ: Clinical implications of the ErbB/epidermal growth factor (EGF) receptor family and its ligands in ovarian cancer. Biochim Biophys Acta 2008, 1785:232-265.

20. Flickinger TW, Maihle NJ, Kung $\mathrm{HJ}$ : An alternatively processed mRNA from the avian c-erbB gene encodes a soluble, truncated form of the receptor that can block ligand-dependent transformation. Mol Cell Biol 1992, 12:883-893.

21. Basu A, Raghunath M, Bishayee S, Das M: Inhibition of tyrosine kinase activity of the epidermal growth factor (EGF) receptor by a truncated receptor form that binds to EGF: role for interreceptor interaction in kinase regulation. Mol Cell Biol 1989, 9:671-677.

22. Lee $H$, Akita RW, Sliwkowski MX, Maihle NJ: A naturally occurring secreted human ErbB3 receptor isoform inhibits heregulin-stimulated activation of ErbB2, ErbB3, and ErbB4. Cancer Res 2001, 61:4467-4473.

23. Cohen MH, Williams GA, Sridhara R, Chen G, McGuinn WD Jr, Morse D, Abraham S, Rahman A, Liang C, Lostritto R, et al:: United States Food and Drug Administration Drug Approval summary: Gefitinib (ZD1839; Iressa) tablets. Clin Cancer Res 2004, 10:1212-1218.

24. Lynch TJ, Bell DW, Sordella R, Gurubhagavatula S, Okimoto RA, Brannigan BW, Harris PL, Haserlat SM, Supko JG, Haluska FG, et al.: Activating mutations in the epidermal growth factor receptor underlying responsiveness of non-small-cell lung cancer to gefitinib. N Engl J Med 2004, 350:2129-2139.

25. Paez JG, Janne PA, Lee JC, Tracy S, Greulich H, Gabriel S, Herman P, Kaye FJ, Lindeman N, Boggon TJ, et al:: EGFR mutations in lung cancer: correlation with clinical response to gefitinib therapy. Science 2004 304:1497-1500

26. Christensen TA, Reiter JL, Baron AT, Maihle NJ: Generation and characterization of polyclonal antibodies specific for human p110 sEGFR. Hybridoma and hybridomics 2002, 21:183-189.

27. Baron AT, Huntley BK, Lafky JM, Reiter JL, Liebenow J, McCormick DJ, Ziesmer SC, Roche PC, Maihle NJ: Monoclonal antibodies specific for peptide epitopes of the epidermal growth factor receptor's extracellular domain. Hybridoma 1997, 16:259-271.

28. Calvano SE, Xiao W, Richards DR, Felciano RM, Baker HV, Cho RJ, Chen RO, Brownstein BH, Cobb JP, Tschoeke SK, et al: A network-based analysis of systemic inflammation in humans. Nature 2005, 437:1032-1037. 
29. Baron AT, Lafky JM, Boardman CH, Balasubramaniam S, Suman VJ, Podratz KC, Maihle NJ: Serum sErbB1 and epidermal growth factor levels as tumor biomarkers in women with stage III or IV epithelial ovarian cancer. Cancer Epidemiol Biomarkers Prev 1999, 8:129-137.

30. Gregorc V, Ceresoli GL, Floriani I, Spreafico A, Bencardino KB, Ludovini V, Pistola L, Mihaylova Z, Tofanetti FR, Ferraldeschi M, et al: Effects of gefitinib on serum epidermal growth factor receptor and HER2 in patients with advanced non-small cell lung cancer. Clin Cancer Res 2004, 10:6006-6012

31. Zampino MG, Magni E, Santoro L, Zorzino L, Dell'Orto P, Sonzogni A, Fazio N, Monfardini L, Chiappa A, Biffi R, de Braud F: Epidermal growth factor receptor serum (sEGFR) level may predict response in patients with EGFR-positive advanced colorectal cancer treated with gefitinib? Cancer Chemother Pharmacol 2008, 63:139-148.

32. Lafky JM, Baron AT, Cora EM, Hillman DW, Suman VJ, Perez EA, Ingle JN, Maihle NJ: Serum soluble epidermal growth factor receptor concentrations decrease in postmenopausal metastatic breast cancer patients treated with letrozole. Cancer Res 2005, 65:3059-3062.

33. Baron AT, Wilken JA, Haggstrom DE, Goodrich ST, Maihle NJ: Clinical implementation of soluble EGFR (sEGFR) as a theragnostic serum biomarker of breast, lung and ovarian cancer. IDrugs 2009, 12:302-308.

34. Berasain C, Perugorria MJ, Latasa MU, Castillo J, Goni S, Santamaria M, Prieto J, Avila MA: The epidermal growth factor receptor: a link between inflammation and liver cancer. Exp Bio/ Med (Maywood) 2009, 234:713-725.

35. Huang $Y$, Tan M, Gosink M, Wang KK, Sun Y: Histone deacetylase 5 is not a p53 target gene, but its overexpression inhibits tumor cell growth and induces apoptosis. Cancer Res 2002, 62:2913-2922.

36. Chang SJ, Wang TY, Tsai CY, Hu TF, Chang MD, Wang HW: Increased epithelial stem cell traits in advanced endometrial endometrioid carcinoma. BMC Genomics 2009, 10:613

37. Wang M, Hu Y, Stearns ME: RPS2: a novel therapeutic target in prostate cancer. J Exp Clin Cancer Res 2009, 28:6.

38. Hammarsund M, Lerner M, Zhu C, Merup M, Jansson M, Gahrton G, KluinNelemans H, Einhorn S, Grander D, Sangfelt O, Corcoran M: Disruption of a novel ectodermal neural cortex 1 antisense gene, ENC-1 AS and identification of ENC-1 overexpression in hairy cell leukemia. Hum Mol Genet 2004, 13:2925-2936.

39. Nakamura Y, Migita T, Hosoda F, Okada N, Gotoh M, Arai Y, Fukushima M, Ohki M, Miyata S, Takeuchi K, et al.: Kruppel-like factor 12 plays a significant role in poorly differentiated gastric cancer progression. Int J Cancer 2009, 125:1859-1867.

40. Xue Y, Bi F, Zhang X, Zhang S, Pan Y, Liu N, Shi Y, Yao X, Zheng Y, Fan D: Role of Rac1 and Cdc42 in hypoxia induced p53 and von Hippel-Lindau suppression and HIF1alpha activation. Int J Cancer 2006, 118:2965-2972.

doi: 10.1186/1476-4598-9-166

Cite this article as: Albitar et al., EGFR isoforms and gene regulation in human endometrial cancer cells Molecular Cancer 2010, 9:166

\section{Submit your next manuscript to BioMed Central} and take full advantage of:

- Convenient online submission

- Thorough peer review

- No space constraints or color figure charges

- Immediate publication on acceptance

- Inclusion in PubMed, CAS, Scopus and Google Scholar

- Research which is freely available for redistribution

Submit your manuscript at www.biomedcentral.com/submit
C Biomed Central 